\title{
Groundwater Balance Study of Pabna District during the Period of 1994-2007
}

\author{
${ }^{1}$ M Saiful Islam, ${ }^{2}$ Alam M K, ${ }^{3}$ Rahman M A

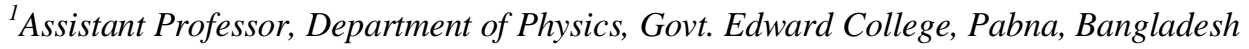 \\ ${ }^{2}$ Assistant Professor, Department of Physics, Pabna University of Science and Technology, Bangladesh \\ ${ }^{3}$ Lecturer, Department of Applied Physics \& Electronic Engineering, University of Rajshahi, Bangladesh
}

\begin{abstract}
The exploration and exploitation of groundwater as a viable resource of water is safer and economical than surface water. Any effort towards the effective use of this precious resource is a service to the mankind. Groundwater is the only source of water supply for drinking and main source of irrigation in the study area. The increasing population and development activities have suddenly increased the demand for consumption of water. The increased demands have stimulated investigations oriented towards quantifications of this resource. The large scale abstraction of groundwater for irrigation, without proper planning and management has caused enormous environmental degradation. So, a detailed study is now essential for the conservation of this important resource in the specific area.

Utilization of groundwater greatly precedes the analysis of discharge and recharge of this inexhaustible resource. The increasing demand placed on it has stimulated to quantify of this resource, which would be the basic of its exploration, management and conservation.

In this work, quantitative analysis of groundwater resources of Pabna district has been made. Seasonal and annual fluctuations of groundwater level of 81 locations have been taken into account. The topography of a terrain is an important factor in ground water studies, as it determines the length of time required for water to accumulate at a given point. The formation and distribution of ground water is greatly influenced by the topographic features of the area. The topographic features also play an important role in selecting the well sites for the detection of suitable groundwater potential zone. The natural feature of the earth surface contributes important information about groundwater. Water head maps are prepared for studying the groundwater flow direction. Annual recharge and discharge of the period of 1994 to 2007 have been estimated. Finally, the groundwater balance study during the period of investigation has been studied.
\end{abstract}

Keywords: Clay, groundwater, irrigation, population, topographic.

\section{INTRODUCTION}

The groundwater is one of the earth's most important resources. It exists whatever water penetrates beneath the surface. The subsurface water generally includes chemical and physical properties, geological environment, natural movement, recovery and utilization. The groundwater becomes a useable resource when the formations in the zone of saturation are perennial. Water is absolutely essential to all life, both animal and plants. In order of important with respect to life and geologic processes water took the position after oxygen. Though almost all groundwater can be thought of as a part of hydrologic cycle, but the groundwater may be classified as to source like Meteoric water, Connate water and Juvennile water (Tolman, 1937).

In recent years, the groundwater scarcity is observed in this area. In many localities, rates of withdrawal have exceeded those of natural replenishment and in some cases it has been observed that the soil water has invaded fresh water strata, in others, pumping cost have become very high. These difficulties, widely published, have lead to conclude that the country is facing groundwater crisis. However, the major goal in the development of agriculture in Bangladesh is to achieve self-sufficiency in food production through intensive irrigation with emphasis on high yielding groundwater development. Bangladesh has abundant surface and groundwater resources, fertile soils and suitable climate for year round cropping. So, investment in water resource development, both surface and groundwater, would contribute substantially to achieve self-sufficiency in food. In groundwater resource study, surface collection areas, underground conduits and reservoirs as well as the behavior of the system must be identified to evaluate the equilibrium equation of hydrologic cycle. 


\section{GENERAL FEATURES OF THE STUDY AREA}

The study area, Pabna district, is located in the south-eastern corner of greater Rajshahi division (Fig.1).The area comprises nine upazillas covering 2371.50 Sq.Km. The two major rivers, the Padma and the Jamuna flowing along the boundaries of the study area are sustaining the environmental balance and socio-economic development. The entire study area is almost a plain land of an average elevation of $14 \mathrm{~m}$ whereas the northwestern part is slightly more elevated with maximum elevation of $22 \mathrm{~m}$. The investigated area is located in the shelf region zone of Bangladesh and was formed by the deposition of sediments carried by the river Padma and its tributaries in the Pleistocene age. The alluvium is composed of clay and sand of different grains. The overall soil quality is very much suitable for groundwater potential. The topmost formation, composed of clay and silt, is underlain by fine, medium and coarse sand. The aquifer system in the investigated area may be schematized into an aquifer of variable thickness.
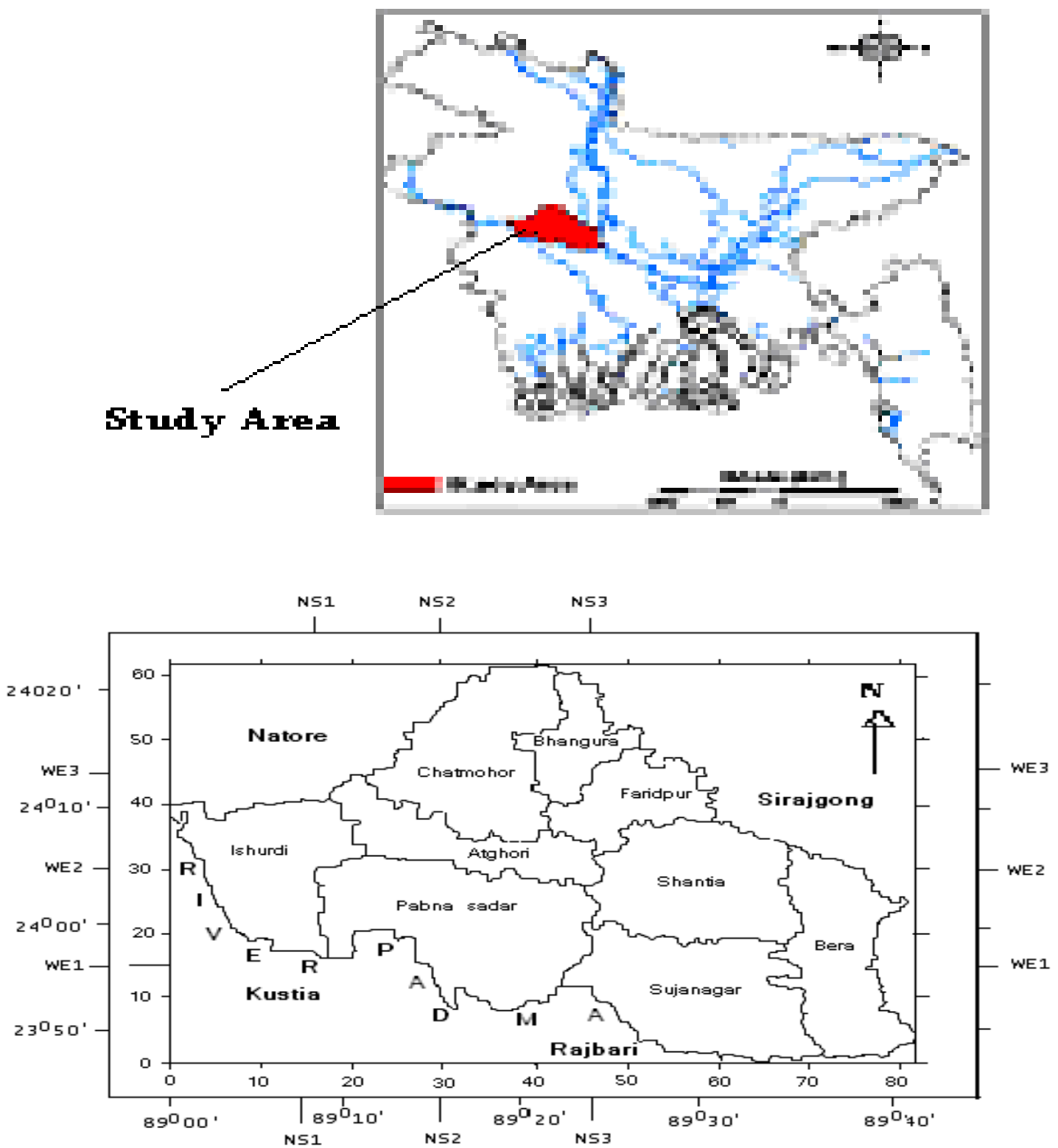

Fig.:1 Representation of the study area map. 


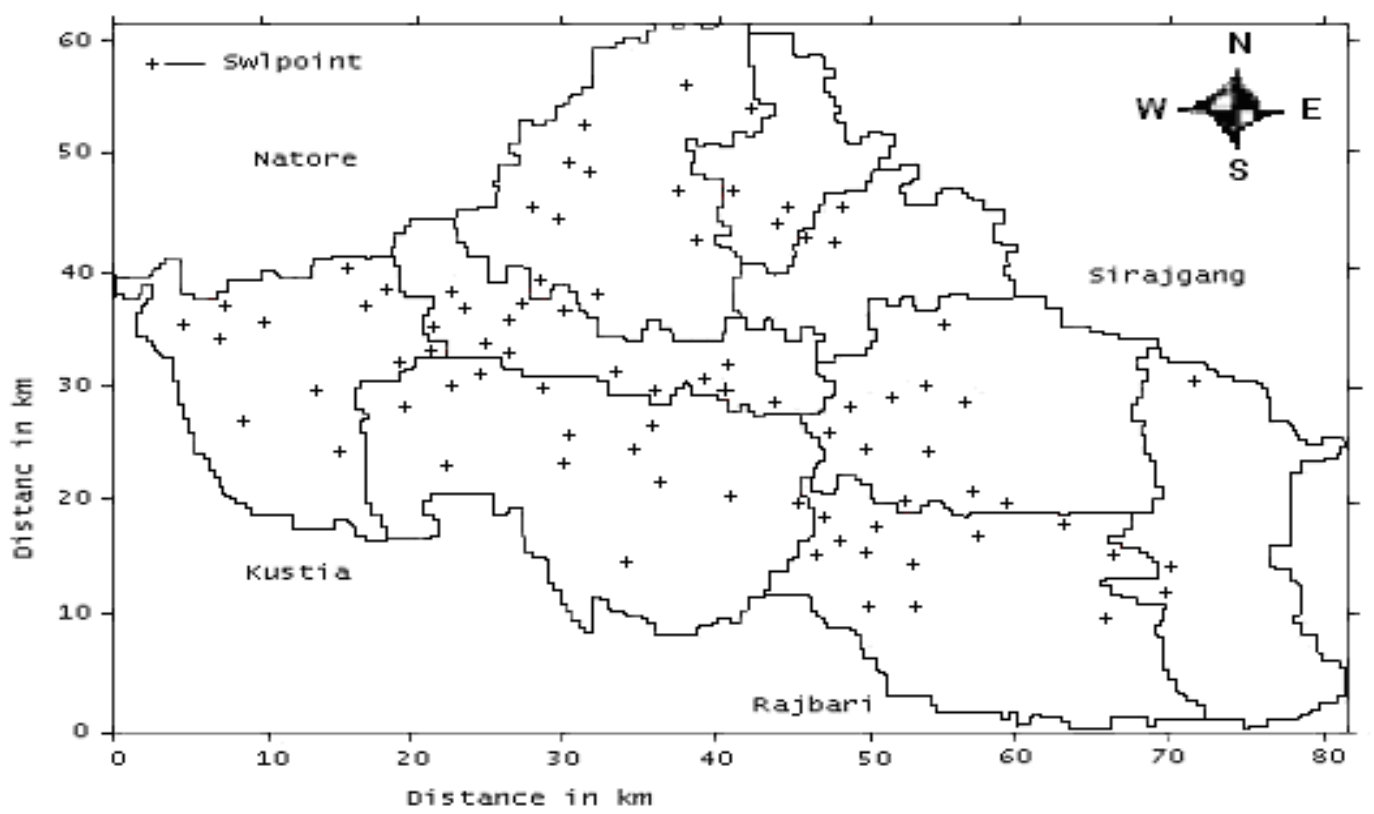

Fig.2: Distribution of static water level measuring points in the study area.

\section{MATERIALS and METHODS}

The successful implication of any research work largely depends not only on the availability and quality of data but also on the methodology. The present research has conducted through data acquisition, analysis and integrated hydro-geological approach. The static water level information is an important key for measuring annual discharge and recharge. So proper management of groundwater chiefly based on the observation of the static water level collected from various locations situated on the investigated area. In this connection, the static water level data of 81 locations during the period of 1994-2007 have been collected from Panasi Project of Pabna district (Fig.2).

For the quantitative assessment of annual recharge and discharge, the water level fluctuations are accounted for both dry and rainy seasons. Borehole information would provide valuable information of subsurface water bearing formations and helps to estimate the different hydro-geological parameters. Finally, the computer simulation of the estimated hydro-geological parameters and lithological information would provide a model of the groundwater regime.

About 300 borehole data were collected from various organizations, The "Panasi Project" under BADC, the Soil Research Institute, Bangladesh Water Development Board (BWDB).

\section{TOPOGRAPHY}

Groundwater is an important natural source of water supply throughout the world. It plays a vital role in the natural system. Topography is a key factor for groundwater storage. Gentle the slope is, lesser will be the run-off and higher the infiltration. In general, the valley regions, rather than the sloppy and top of the hillock, are considered more favorable for groundwater exploration. For studying the surface feature of the study area a shaded contour map of surface elevation with $2 \mathrm{~m}$ interval has been prepared (Fig.3). From the map it is clear that the western side is a high land, the southern and the southeastern sides are comparatively a low land. Some regions of the northern side are also a low land.

The natural feature of the earth surface of the study area is prepared with respect to the mean sea level (msl.) as shown in Fig.4. From the prepared map it is observed that the surface is slopping downward towards the southeast side. The groundwater flow in the middle portion of the study area may be influenced by the irrigation slope pattern of the area. The perceived valley in the map may be used for well site. A large pocket is also observed in the various parts of the study area, which may have sufficient ground water potentiality. 


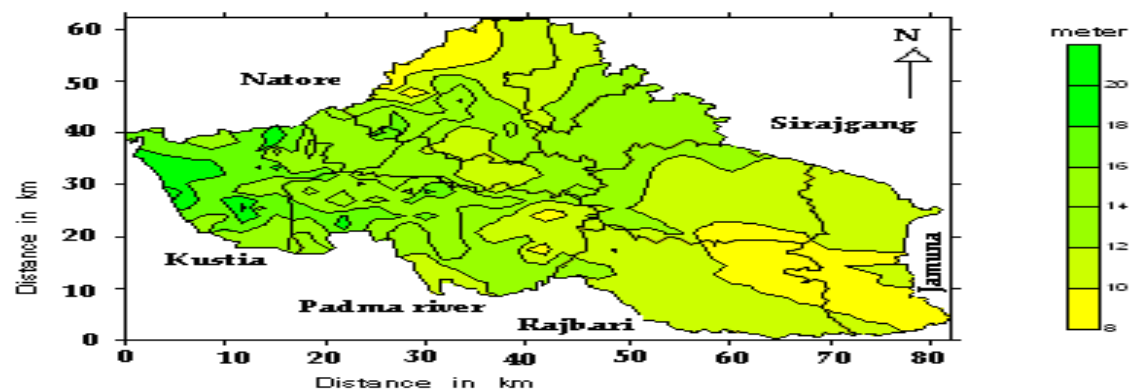

Fig.Error! No text of specified style in document.: Contour map of elevation of the earth surface of the study area ( $2 \mathrm{~m}$ interval)

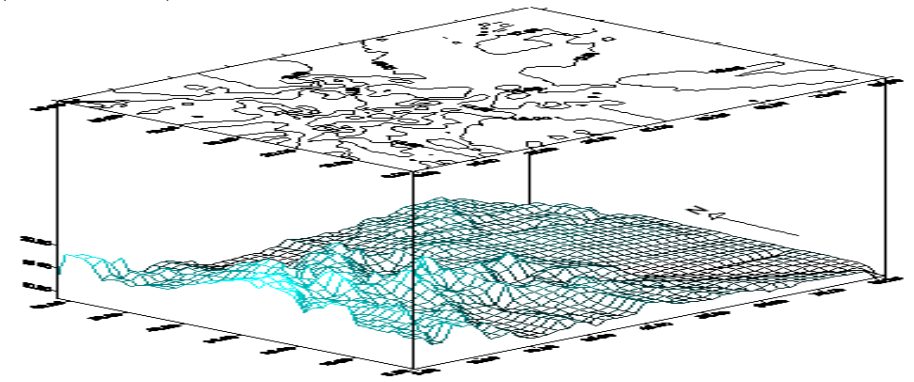

Fig.4: Physical shape of the earth surface of the study area with respect to mean sea level

\section{WATER HEAD MAP}

Groundwater moves in the direction of the decreasing head. The head at a point is taken as the elevation, above an arbitrary datum, of the top of a static column of water that can be supported above the point. The elevation of the point above the datum is called the elevation head. In a complete groundwater survey it is necessary to identify the true gradients of the water head surface, relative to a datum plane. The position of the water table with respect to the datum is generally known as Water Head Position (W.H.P). The aerial variation of water head with respect to mean sea level (msl) represents the potentiometric surface. The water head position with respect to (msl) of the study area the contour map has been prepared and surface view of the water head position of the study area of dry and rainy seasons of the year 1993-2008 are shown in Fig.5 and Fig.6 respectively. These figures illustrate that the flow of underground water originates from the north-western corner and western side of the study area and moving towards northern, eastern and southeastern corners.

From the water head contour maps it is also observed that there is a decreasing trend of water head position from the year 1993 to 2008 in dry period. This indicates that the water level is going downward. After the monsoon, almost same effect is observed. Although the fluctuations of the water head positions between in dry and wet seasons of different years are the same, but it could not cover up the initial position of the year of 1993.

\section{VOLUMETRIC ANALYSIS OF RECHARGE AND DISCHARGE}

A quantitative assessment of groundwater recharge and discharge has been made for the study area. In the present work annual recharge and discharge have been estimated only considering the fluctuation of groundwater table. In the recharge estimation, the rising of groundwater table from dry to rainy seasons is considered and volume between them is calculated. This volume is multiplied by the specific yield of respective formations saturated with groundwater to have the recharged volume of water. The partial volumes of different formations are calculated carefully. Similarly, for discharge estimation, volume covered by shifting water table from rainy to dry season is considered. This can be formulated as follows:

$$
\begin{aligned}
\mathrm{Q} & =\mathrm{V} \cdot \mathrm{S}_{\mathrm{y}} \\
& =\mathrm{V}_{1} \cdot \mathrm{S}_{\mathrm{y} 1}+\mathrm{V}_{2} \cdot \mathrm{S}_{\mathrm{y} 2}
\end{aligned}
$$

Where, $\mathrm{Q}=$ recharged / discharged volume of water,

$\mathrm{V}=$ total volume between water-tables,

$\mathrm{S}_{\mathrm{y}}=$ specific yield of the formation,

$\mathrm{V}_{1}=$ partial volume within first formation, 
$\mathrm{S}_{\mathrm{y} 1}=$ specific yield of first formation

$\mathrm{V}_{2}=$ partial volume within second formation,

$\mathrm{S}_{\mathrm{y} 2}=$ specific yield of second formation.

As the water table in the study area fluctuates within two formations - top clay and fine sand; so, during recharge and discharged calculations only these two formations have been taken into account. For the estimation of total volume of water in the present computation the specific yields of clay and fine sand are considered as $3 \%$ and $23 \%$ respectively. During the estimation of volume of water recharged and discharged during the period 1994-2007, first the amount of water discharged in the year of 1994 is estimated considering the water level fluctuations between after rainy of 1993 and dry seasons of the years 1994 and similarly, the volume of water discharged in the year of 1994 is calculated considering the fluctuations of water level between the post-monsoon and pre-monsoon of 1994.In this process, the volume of recharged and discharged water have been calculated for the different years. The estimated annual recharge and discharge of the years 1994-2007 are presented in the Table-

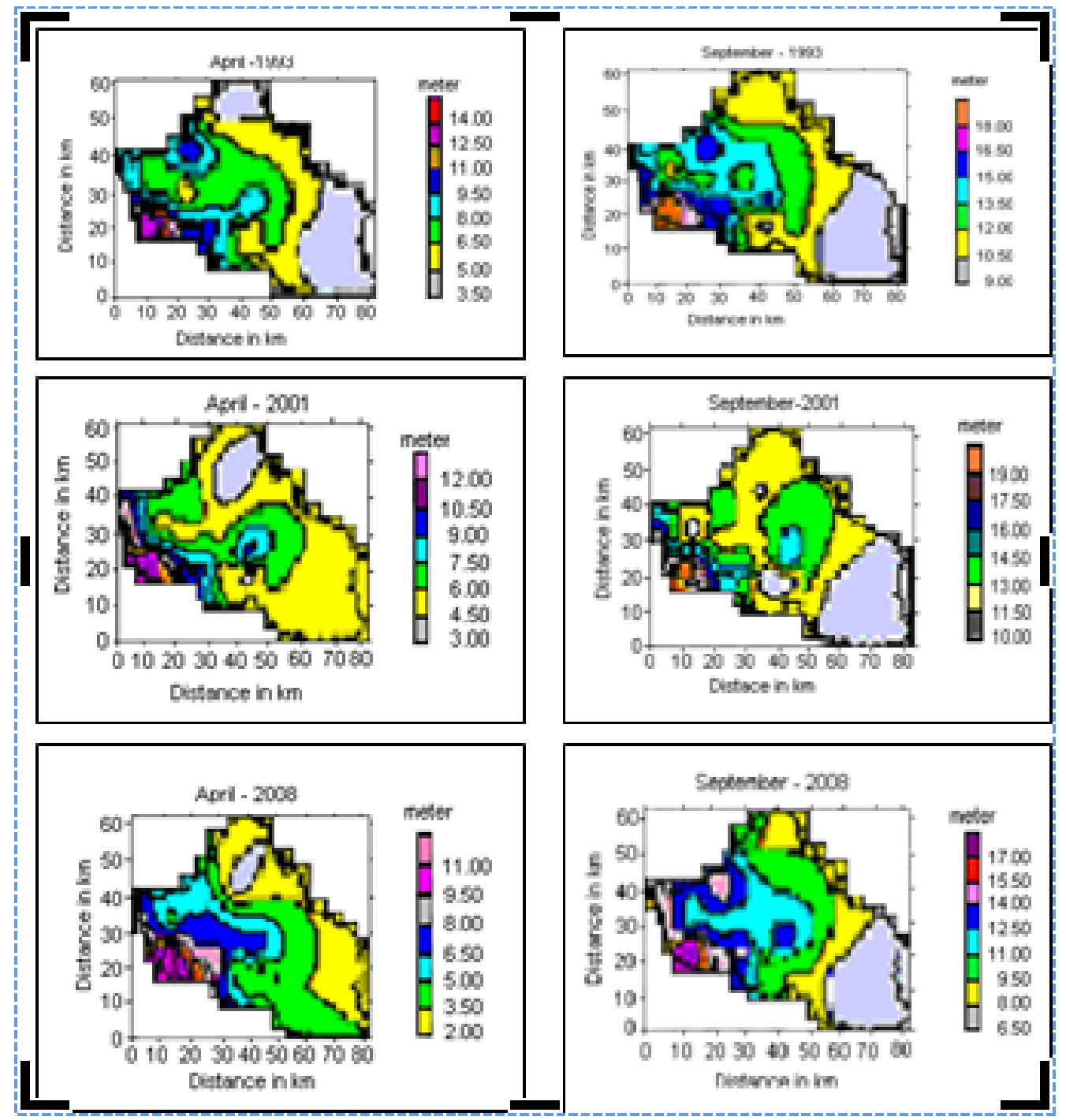

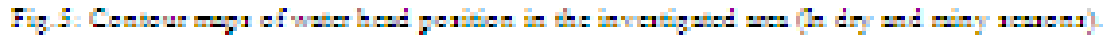

Fig.5: Contour maps of water head position in the investigated area (In dry and rainy seasons). 

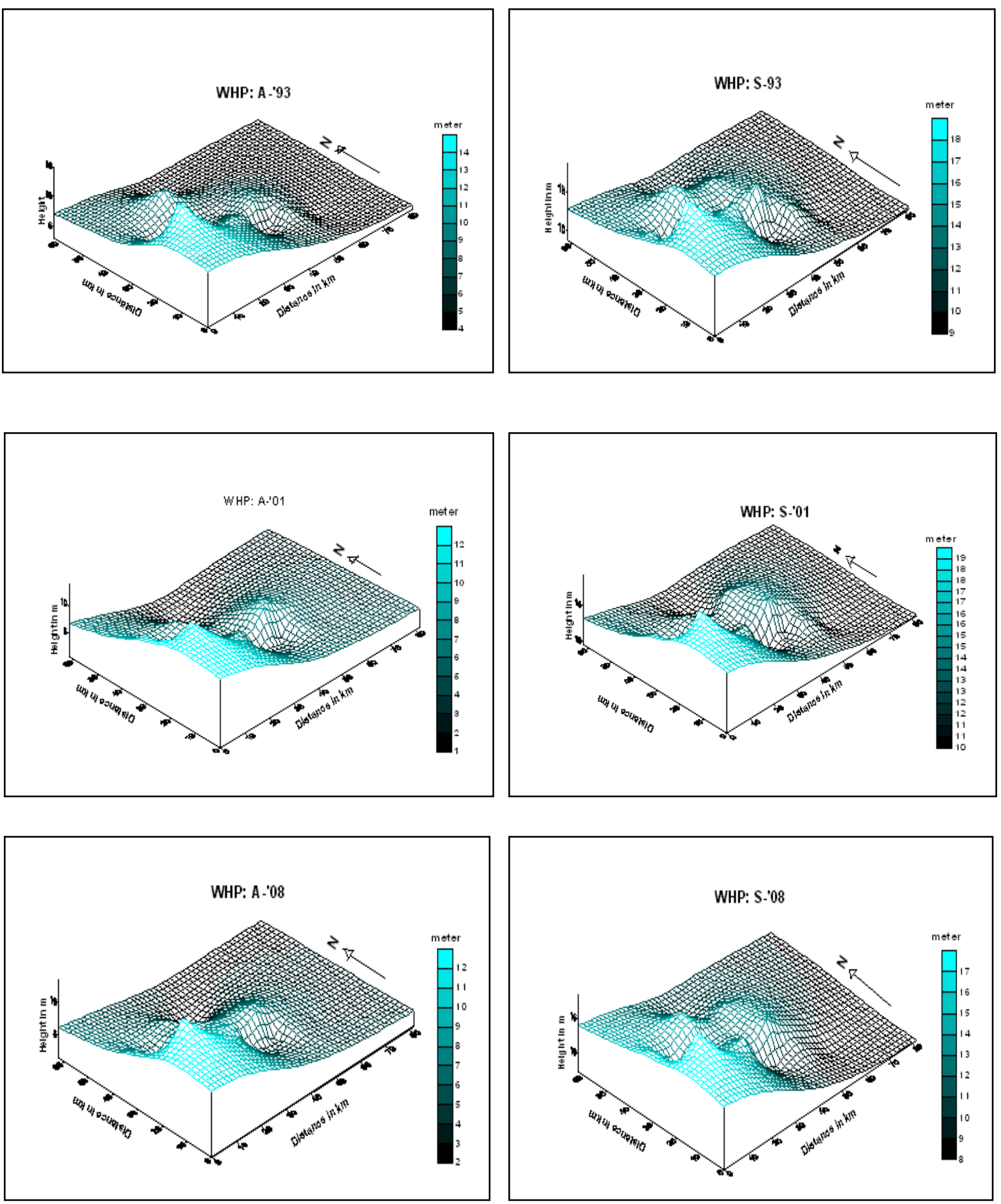

Fig.6: Water head variation in the different years between dry (April) and rainy (Sept.) seasons.

The Histogram of Fig.7 shows the total volume of recharged and discharged water along with rainfall of the investigated area during the period 1996-2007. Except the years of 1998, 2003 and 2007, the discharge is greater than that of recharge. 


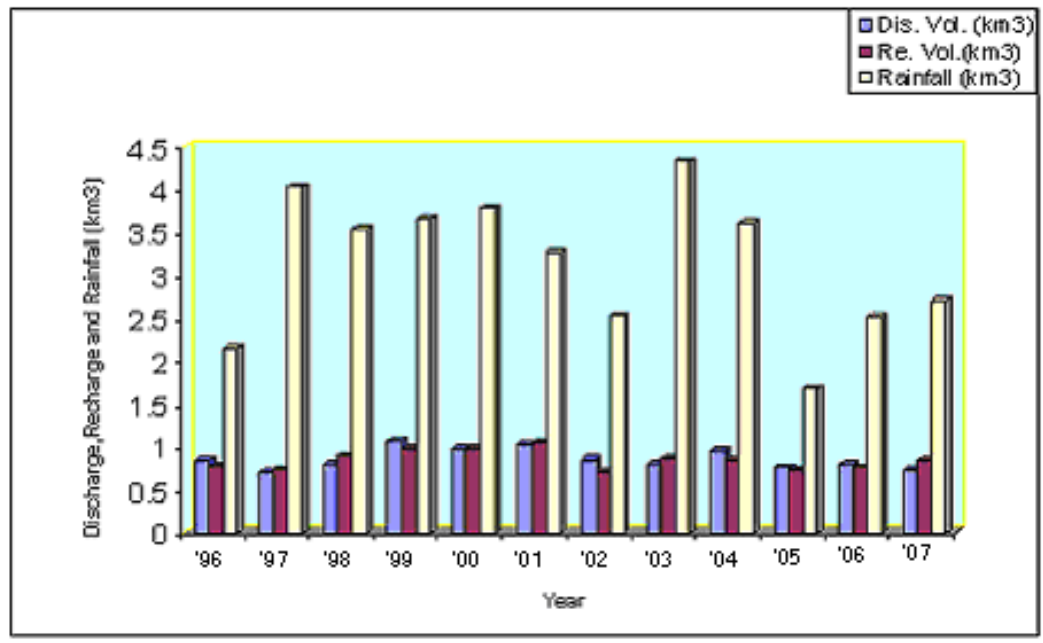

Fig.7: Representation of Discharge, Recharge and Rainfall of the study area.

\section{GROUNDWATER BALANCE STUDY}

The main objective of this groundwater investigation is to define the present hydro-geological regime and groundwater balance $\mathrm{n}$ detail to allow the prediction of the effects on water levels of additional discharge and recharge. Groundwater reservoirs receive their greatest replenishment from precipitation and stream flow. Thus, a groundwater reservoir is said to be used efficiently if its operation is on the basis of a balance of each year between recharge and discharge. If the balance is achieved during a climatic cycle of several years' duration, however, the groundwater reservoir can provide hold over storage from wet years for the drier years when the need for water is greatest (Thomas, 1951).But if groundwater is withdrawn at a rate exceeding the recharge, different types of hazards may occur such as (i) declination of water level, (ii) deterioration of water quality, and (iii) destruction of hydraulic properties. The present study area suffers from some of the above problems for large scale abstraction of groundwater due to irrigation. So, with a view to management and further development of groundwater an assessment of groundwater resources of the study area has been made on the basis of input-output stresses.

Groundwater balance for the study area is worked out using the following relation assuming the natural groundwater inflow to be equal to the groundwater outflow,

$$
\Delta \mathrm{S}=\mathrm{I}-\mathrm{O}
$$

Where, $\Delta \mathrm{S}=$ Change in storage,

$\mathrm{I}=$ annual input to groundwater system,

$\mathrm{O}=$ annual output from groundwater system.

The groundwater balance is carried out with the observed data for the period 1994 to 2007 and presented in table- 1 . It is clearly observed from the table that the amount of water overdraft during the tenure (1994-2007) is $-0.12 \mathrm{~km}^{3}$. This over- exploitation of underground water has resulted an average declination of $0.26 \mathrm{~m}$ of water table in the area studied. From Fig.5 and Fig.6, a permanent declination of groundwater level have also been identified.

Table-1: Annual recharge, discharge and balance data.

\begin{tabular}{|c|c|c|c|c|}
\hline Period & $\begin{array}{c}\text { Annual Discharge } \\
(\mathrm{O}) \\
\left(\mathrm{Km}^{3}\right)\end{array}$ & $\begin{array}{c}\text { Annual Discharge } \\
(\mathrm{I}) \\
\left(\mathrm{Km}^{3}\right)\end{array}$ & $\begin{array}{c}\text { 6\#Balance } \\
\Delta \mathrm{S}=\mathrm{I}-\mathrm{O} \\
\left(\mathrm{Km}^{3}\right)\end{array}$ & $\begin{array}{c}\text { Net Balance } \\
\left(\mathrm{Km}^{3}\right)\end{array}$ \\
\hline 1994 & 0.79 & 0.69 & -0.10 & \\
\hline 1995 & 0.85 & 0.97 & 0.12 & \\
\hline 1996 & 0.84 & 0.78 & -0.06 & \\
\hline 1997 & 0.71 & 0.75 & 0.04 & \\
\hline 1998 & 0.80 & 0.90 & 0.10 & \\
\hline
\end{tabular}




\begin{tabular}{|l|l|l|l|l|}
\hline 1999 & 1.07 & 0.98 & -0.09 & \\
\hline 2000 & 0.97 & 0.98 & 0.01 & -0.12 \\
\hline 2001 & 1.04 & 1.06 & 0.02 & \\
\hline 2002 & 0.85 & 0.70 & -0.15 & \\
\hline 2003 & 0.80 & 0.87 & 0.07 & \\
\hline 2004 & 0.95 & 0.84 & -0.11 & \\
\hline 2005 & 0.77 & 0.73 & -0.04 & \\
\hline 2006 & 0.80 & 0.76 & -0.04 & \\
\hline 2007 & 0.73 & 0.84 & 0.11 & \\
\hline
\end{tabular}

\section{CONCLUSION}

Bangladesh predominantly is an agricultural country. It plays a significant role in the overall economic development of the country. The Bangladesh Government has identified agriculture and rural development as the topmost priority sectors for rapid poverty alleviation. With about 21.11 percent of GDP contributed by agriculture and another 36 percent by the rural non-firm sector, the rural economy as a whole contributes more than 60 percent of the total GDP. So, it needs not be said time and again that there is no alternative to agriculture for the survival and development of the nation. Our nation had rightly realized that the gravity of agriculture in the beginning of our new journey as an independent country; and accordingly, soon, after the achievement of our independence (The Guardian).

Groundwater is an important segment of the hydrologic cycle and constitutes about one third of world's fresh water reserves. Being relatively free from the pathological organism, turbidity, radio-chemical and biological contaminations, it has distinct advantages over surface water resources. It is the most dependable resource. Its chemical composition is nearly constant unless there is sudden contamination from industries or mines and is available almost everywhere on land phases. Therefore, the major replenishable resource of water interests all the engineers connected with water supply and irrigation (K.C.Patra 2001). Exploration of groundwater reservoir as a viable source of fresh water is safer and economical than surface water. The need to develop appropriate models for exploration,

The irrigation in the study area part is almost entirely dependent upon groundwater and is becoming increasingly important for crop production. But the overexploitation leads to the fall of water table in this area.

Therefore, to assess the sustainability of this it is required to examine the nature of the aquifer system precisely. The presence of water table in the aquifer system of the investigated area indicates that the system is unconfined in nature and the water table lies within the sandy formation. The aim of the work is to target the groundwater reserve in the study area that can be used for drinking, domestic supplies and irrigation.

From the volumetric analysis of recharge, discharge and rainfall of the study area it is observed that the recharge amount of groundwater is less than that of the discharge. Although, the rainfall of the study area is enough. From the above observation it is obviously prevailed that overexploitation of groundwater should be prohibited for the sustainable groundwater reserve for year round cropping system and other uses.

So, steps must be taken for continuous monitoring of water level fluctuations and for optimal exploration and proper management of the groundwater system the number of wells and their pumping rates should be controlled.

The water head position of the investigated area has been prepared for studying the direction of groundwater flow throughout the aquifer system. The flow directions show that the subsurface water flow of the investigated area has originated in the northwestern corner and is directed towards the southeastern and southwestern corners. The distribution of groundwater is

greatly influenced by the topography of the area. These parameters are very important for selecting the groundwater potential zones.

\section{Acknowledgement}

The work has been accomplished in the Geophysics Laboratory of the Department of Applied Physics and Electronic Engineering of Rajshahi University with the full co-operation of the institution of 'Panasi Project' under the department of Bangladesh Agriculture evelopment Corporation (BADC), Pabna, Bangladesh and the direct supervision of my supervisor who is appointed as a guide for this research work. I am very much grateful to the stated institution for giving us relevant information about the work. 


\section{References}

[1] Aziz,M.A., 1986, Water Supply Engineering, Hafiz Book Centre, Dhaka, P.320.

[2] Khan, F. H., 1991, Geology of Bangladesh, Wiley Eastern Limited, India. P.181-182.

[3] Mahajan,G.,1993, Groundwater Recharge, S.B. Nangia, 8/81 Pungabi Bagh, New Delhi, India. P.49.

[4] Patra, K.C., 2001, Hydrology and Water Resources Engineering, Narosa Publishing House, New Delhi, India. P.195.

[5] Tolman, C.F.,1937, Ground water, McGraw-Hill Book Company, Inc., P.1-5.

[6] Zilla Unnayan Porikkama,Pabna,2005, Department of Mass Communication, Ministry of Information, B.G. Press, Dhaka, Bangladesh P.18.

[7] Thomas, H.E.,1951, The conservation of groundwater, McGraw-Hill Book Company, Inc., P.327.

[8] Islam, M.S.,2011, Unpublished M.Phil Thesis, Department of Applied Physics and Electronic Engineering, Rajshahi University, Rajshahi, P.140. 